\title{
Influence of Oxidation and Deposition Process on Electrical Properties of Graphene Films
}

\author{
Olena Okhay $^{1}$, Rahul Krishna ${ }^{1}$, Luis M. Guerra ${ }^{2}$, João Ventura ${ }^{2}$, Elby Titus ${ }^{1}$ and Jose Gracio ${ }^{1}$ \\ 1. Nanotechnology Research Division, Center for Mechanical Technology and Automation (TEMA), Department of Mechanical \\ Engineering, University of Aveiro, Portugal \\ 2. Materials Physics Institute of the University of Porto (IFIMUP), Porto 4169-007, Portugal
}

Received: September 15, 2014 / Accepted: October 09, 2014 / Published: October 25, 2014.

\begin{abstract}
The influence of reducibility of graphene oxide (GO) by hydrazine hydrate on their electrical properties was investigated. Reduced GO (rGO) films were obtained by mixing of graphene oxide (GO) solution with hydrazine hydrant $(\mathrm{HH})(10 \%$ and $50 \%$ of concentration) and final dropping on Si substrate or by dropping of GO solution on Si substrate already covered by $\mathrm{HH}(10 \%$ or $50 \%$ of concentration). Electrical measurements show semiconductor value ofelectrical conductivity for the samples with high concentration of $\mathrm{HH}\left(10^{-4} \mathrm{~A}\right.$ at applied $\left.\pm 10 \mathrm{~V}\right)$. At the same time low concentration of $\mathrm{HH}$ leads to much smaller value of conductivity $\left(10^{-7} \mathrm{~A}\right.$ at $\left.\pm 10 \mathrm{~V}\right)$.
\end{abstract}

Key words: Graphene oxide, process preparation, electrical properties.

\section{Introduction}

Graphene (reduced graphene oxide, rGO) is a two-dimensional material with unique transport and physicochemical properties and potential applications in sensors, super-capacitors and hydrogen storage, etc. [1]. Graphene can be obtained from graphene oxide (GO) and a lot of preparation techniques have been reported [2]. By nature, is electrically insulating and thus cannot be used, without further processing, as a conductive nanomaterial, graphene-based platelets on a large scale [1], in composites [3], paper-like materials and thin films [4], as a coating layer [5], and as transparent conductive films [6]. However, GO has a wide range of oxygen functionalities, such as 1,2-epoxide and alcohol groups on the basal planes, and carboxyl and ketone groups at the edges $[7,8]$. In addition, the presence of the oxygen functional groups makes GO thermally

Corresponding author: Olena Okhay, Ph.D., research field: material science. E-mail: olena@ua.pt. unstable, as it undergoes pyrolysis at elevated temperatures $[9,10]$. Notably, it has been demonstrated that the electrical conductivity of GO can be restored close to the level of graphite by chemical reduction [11-14]. Due to that hydrazine was proposed as an efficient reducing agent for obtaining grapheme [15]. However, influence of hydrazine hydrate on electrical properties of graphene has not been studied in great detail.

\section{Experiments}

Solution of graphene oxide (GO) were prepared by dissolving of GO powder (obtained by Hummer-based method) in water. Reduction of GO was achieved by using hydrazine $\left(\mathrm{N}_{2} \mathrm{H}_{4}\right)$ hydrate $(\mathrm{HH})$ in two different concentrations: $10 \%$ and $50 \%$ and in two different ways. For first two samples $\mathrm{GO}+10 \% \mathrm{~N}_{2} \mathrm{H}_{4}$ or $\mathrm{GO}+$ $50 \% \mathrm{~N}_{2} \mathrm{H}_{4}$ solutions (1:1) were dropped on $\mathrm{Si}$ substrates after long ultrasonic stirring and dried (samples GO $+10 \% \mathrm{~N}_{2} \mathrm{H}_{4}$ and $\mathrm{GO}+50 \% \mathrm{~N}_{2} \mathrm{H}_{4}$, respectively). And for the next two samples solution of 
GO was dropped on Si substrate preliminary covered by thin layer of $\mathrm{N}_{2} \mathrm{H}_{4}$ with concentrations $10 \%$ or $50 \%$ (samples GO on $10 \% \mathrm{~N}_{2} \mathrm{H}_{4}$ and GO on $50 \% \mathrm{~N}_{2} \mathrm{H}_{4}$ ). The obtained samples were studied by powder X-ray diffraction (XRD) at room temperature in a continuous scanning mode (step: 0.02 and time: $10 \mathrm{~s}$ ) on a Siemens D500 diffractometer with secondary monochromator $\mathrm{CuK} \alpha \mathrm{X}$-radiation in the range $\left(2 \theta: 5-60^{\circ}\right), 40 \mathrm{kV}, 30$ $\mathrm{mA}$. Morphology of the obtained samples was checked using a Scanning Electron Microscope. The current-voltage (I-V) cycles were obtained using a Keithley Source Meter 2410C and manual probes with tungsten tips at room temperature.

\section{Results and Discussion}

XRD spectra of studied samples present broad peak and its position (about 25-30 $0^{\circ}$ is similar for all analyzed films (Fig. 1). Such peak corresponds to peak in reduced grapheme [17] and it is possible to say, that all analyzed samples represented really rGO films.

Scanning electron microscope (SEM) analyze of samples of reduced $\mathrm{GO}$ that obtained by using of $\mathrm{HH}$ with concentration $50 \%\left(\mathrm{GO}+50 \% \mathrm{~N}_{2} \mathrm{H}_{4}\right.$ in Fig. 2 and GO on $50 \% \mathrm{~N}_{2} \mathrm{H}_{4}$ in Fig. 3) does not show significant difference. In both cases the reduced GO films are transparent and continue.

The main difference between studied films was found during the measurements of electrical properties (volage-current dependency). It was found that reducing of $\mathrm{GO}$ by $\mathrm{HH}$ with high concentration (50\%) (sample GO $+50 \% \mathrm{~N}_{2} \mathrm{H}_{4}$ ) leads to semiconductor behavior of graphene and show high value of current $\left(10^{-4} \mathrm{~A}\right)$ (Fig. 4a). At the same time, reducing of GO by $\mathrm{HH}$ with low concentration (10\%) (sample GO + $10 \% \mathrm{~N}_{2} \mathrm{H}_{4}$ ) leads to much smaller value of conductivity (current $10^{-6} \mathrm{~A}$ ) (Fig. 4b). However, samples obtained by dropping of GO solution on preliminary covering of $\mathrm{Si}$ substrate by $\mathrm{N}_{2} \mathrm{H}_{4}$ with concentration equal $50 \%$ (sample GO on $50 \% \mathrm{~N}_{2} \mathrm{H}_{4}$ ) shows value of the current about $10^{-4} \mathrm{~A}$ that is similar to sample $\mathrm{GO}+50 \% \mathrm{~N}_{2} \mathrm{H}_{4}$ but form of the curve is more linear (Fig. 4c). Fig. 4d shows the behavior of current for the samples obtained by dropping of GO solution on covered substrate by HH with $10 \%$ (sample GO on $10 \% \mathrm{~N}_{2} \mathrm{H}_{4}$ ) and this value of the current is the lowest one in comparison to others films $\left(10^{-7} \mathrm{~A}\right)$.

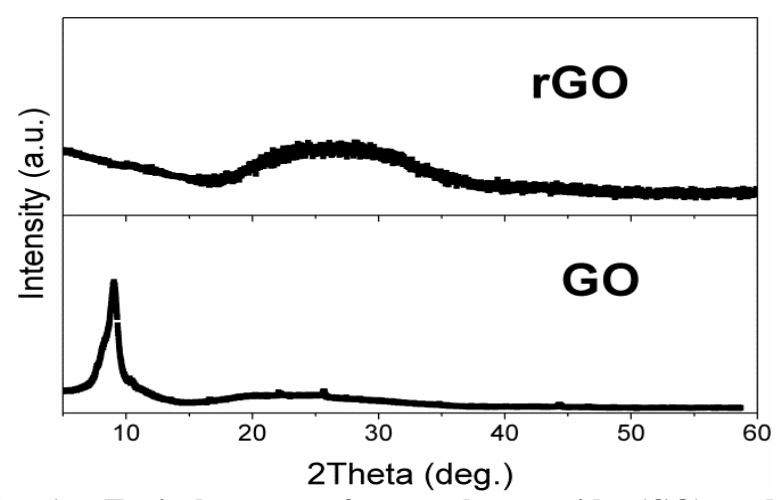

Fig. 1 Typical spectra for graphene oxide (GO) and reduced graphene (rGO) films studied in the current work.
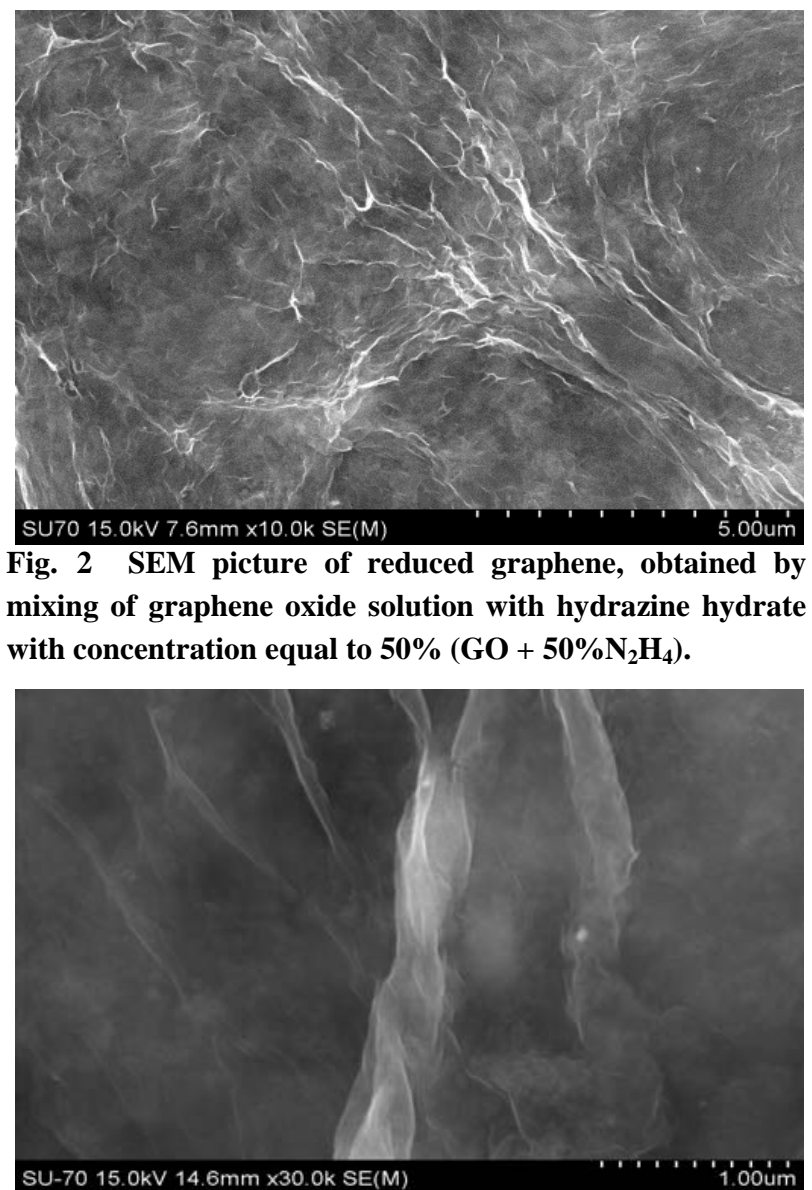

Fig. 3 SEM picture of reduced graphene, obtained by deposition of graphene oxide solution on thin layer of hydrazine hydrate with concentration equal to $50 \%$ (GO on $\left.50 \% \mathrm{~N}_{2} \mathrm{H}_{4}\right)$. 

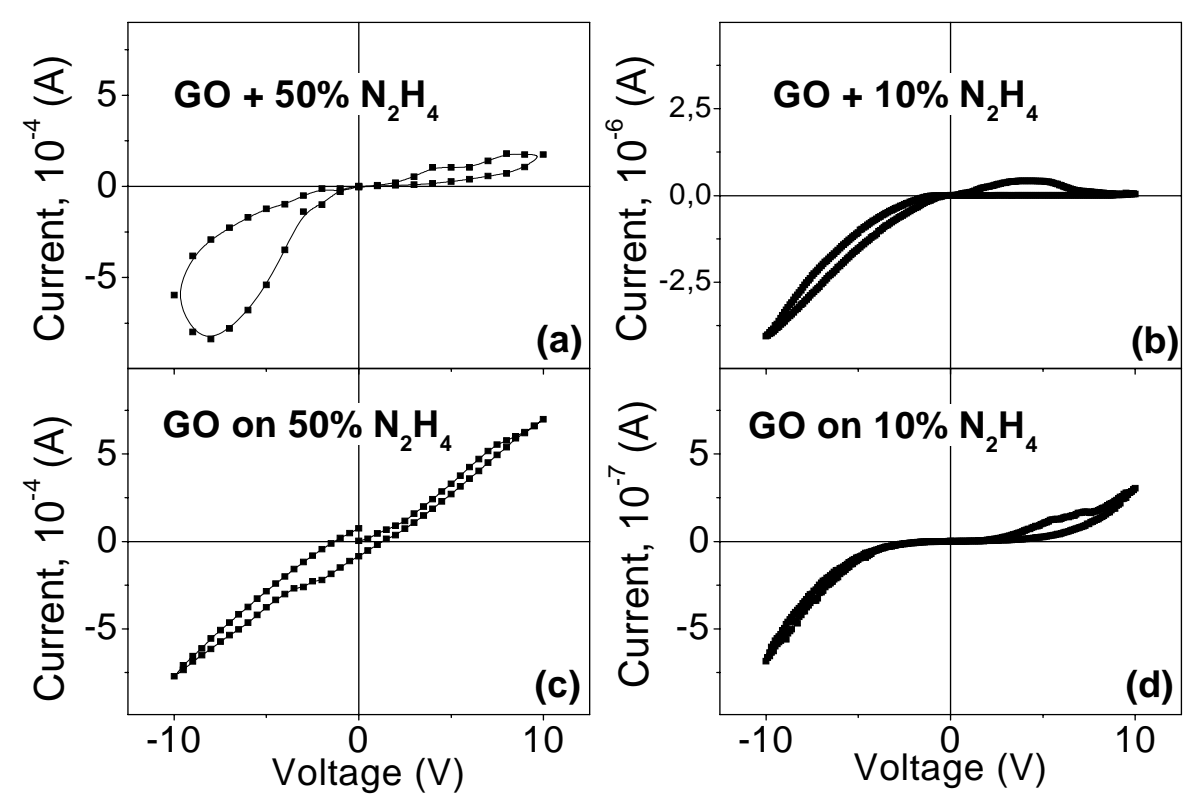

Fig. 4 I-V data of graphene films obtained by mixing GO (a) with HH 50\%, (b) with HH $10 \%$, by deposition of GO (c) on thin layer of $\mathrm{HH} 50 \%$ and (d) on $\mathrm{HH} 10 \%$.

Such structural results clearly show that reduction of the exfoliated GO results in considerable removal of oxygen. The same conclusion can be reached through the electrical conductivity measurements since the observed increase in conductivity upon reduction of GO requires that conductive pathways of conjugated carbon atoms be re-established. Thus, the characterization of the reduced GO indicates that the hydrazine treatment results in the formation of unsaturated and conjugated carbon atoms, which in turn imparts electrical conductivity and it is in agreement with published already [18]. Moreover, covering of substrate by hydrazine hydrate before deposition of GO films leads to more homogeneous distribution of hydrazine between surface of substrate and GO film that could lead to better reducing of graphene oxide top filmand results in the higher value of electrical conductivity. Moreover, according to the better electrical results obtained for films deposited on substrate with layer of hydrazine hydrant, it is possible to suppose, that during the such way of preparation of samples all bonds (C-O-C, OH, $\mathrm{C}=\mathrm{O}$ ) are well reduced in opposite to reducing by simple mixing of GO and HH [16].

\section{Conclusions}

According to the obtained results, hydrazine with high concentration in $50 \%$ leads to fast reducing of GO and these samples shown semiconductor behavior with current about $10^{-4} \mathrm{~A}$ and deposition of GO on covered substrate by $\mathrm{HH}$ with $50 \%$ could be perspective.

\section{Acknowledgments}

O. O. acknowledges FCT for financial support (SFRH/BD/77704/2011).

\section{References}

[1] S. Park, R.S. Ruoff, Chemical methods for the production of graphenes, Nat. Nanotechnol. 29 (2009) 217.

[2] C. Berger, Z. Song, X. Li, X. Wu, N. Brown, C. Naud, et al., Electronic confinement and coherence in patterned epitaxial grapheme, Science 312 (2006) 1191.

[3] H. Wang, Q. Hao, X. Yang, L. Lu, X. Wang, Effect of graphene oxide on the properties of its composite with polyaniline, ACS Appl Mater Interfaces 2 (2010) 821.

[4] H. Chen, M.B. Muller, K.J. Gilmore, G.G. Wallace, D. Li, Mechanically strong, electrically conductive, and biocompatible graphene paper, Adv. Mater. 20 (2008) 3557.

[5] T.H. Han, W.J. Lee, D.H. Lee, J.E. Kim, E.Y. Choi, S.O. Kim, Peptide/graphene hybrid assembly into core/shell 
nanowires, Adv Mater.22 (2010) 2060.

[6] G. Eda, G. Fanchini, M. Chhowalla, Large-area ultrathin films of reduced graphene oxide as a transparent and flexible electronic material, Nat. Nanotechnol. 3 (2008) 270.

[7] A. Lerf, H. He, M. Forster, J. Klinowski, Structure of graphite oxide revisited, J. Phys. Chem. 102 (1998) 4477.

[8] H. He, J. Klinowski, M. Forster, A. Lerf, A new structural model for graphite oxide, Chem. Phys. Lett. 287 (1998) 53.

[9] H.P. Boehm, A. Clauss, G.O. Fischer, U. Hofmann, Thinnest carbon films, Z. Naturforsch. 17 B (1962) 150.

[10] H.P. Boehm, A. Clauss, G.O. Fischer, U. Hofmann, Das Adsorptions verhaltensehrdünner Kohlenstoff-Folien, Z. Anorg. Allg. Chem. 316 (1962) 119.

[11] B. Bourlinos, D. Gournis, D. Petridis, T. Szabo, A. Szeri, I. Dekany, Graphite oxide: Chemical reduction to graphite and surface modification with primary aliphatic amines and amino acids, Langmuir 19 (2003) 6050.
[12] U. Hofmann, A. Frenzel, The reduction of graphite oxide with hydrogen sulphide, Kolloid-Z 68149 (1934).

[13] P. Xiao, M. Xiao, P. Liu, K. Gong, Direct synthesis of a polyaniline-intercalated graphite oxide nanocomposite, Carbon 38 (2000) 626.

[14] N.A. Kotov, I. Dekany, J.H. Fendler, Ultrathin graphite oxide-polyelectrolyte composites prepared by self-assembly: Transition between conductive and non-conductive states, Adv. Mater. 8 (1996) 637.

[15] P. Zhu, M. Shen, S. Xiao, D. Zhang, Experimental study on the reducibility of graphene oxide by hydrazine hydrate, Physica B 406 (2011) 498.

[16] S. Park, J. An, J. R. Potts, A. Velamakanni, S. Murali, R.S. Ruoff, Hydrazine-reduction of graphite- and graphene oxide, Carbon 49 (2011) 301.

[17] S. Stankovich, D.A. Dikin, R.D. Piner, K.A. Kohlhaas, A. Kleinhammes, Y. Jia, et al., Synthesis of graphene-based nanosheets via chemical reduction of exfoliated graphite oxide, Carbon 45 (2007) 1558. 